\title{
Adscripciones religiosas en Pantelhó, Chiapas. Un proceso DE CAMBIO SOCIAL
}

\author{
Susana Villasana Benítez \\ José Antonio Zebadúa Luna
}

Resumen: El objetivo de este trabajo es dar a conocer cómo ha sido el proceso de cambio religioso a credos no católicos, a través de testimonios. En Pantelhó, Chiapas, el cambio religioso ha provocado división entre la población, desacuerdo por parte de los católicos y separación, rompiendo lazos de amistad y familiares. Estos cambios en las relaciones sociales se observaron en los testimonios que se presentan más adelante.

Palabras clave: adscripción y conversión religiosa, diversidad étnica y religiosa, cambio social.

Enviado a dictamen: 21 de enero de 2009

Aprobación: 06 de mayo de 2009

Revisiones: 1

Susana Villasana Benítez, doctora en Ciencias Sociales por El Colegio de la Frontera Norte, labora en el Instituto de Estudios Indígenas de la Universidad Autónoma de Chiapas, San Cristóbal de Las Casas, Chiapas, México. Temas de especialización: sociología de la religión, organización social, identidad étnica, estudios de población. Correo electrónico: slvb@yahoo.com.mx. José Antonio Zebadúa Luna, licenciado en Sociología, Facultad de Ciencias Sociales de la Universidad Autónoma de Chiapas, CECyTECH, San Cristóbal de Las Casas, Chiapas, México. Tema de especialización: Sociología de la religión. Correo electrónico: jazpuma_500@hotmail.com.
Abstract: The goal of this paper is to present how it has been the process of religious change to non-Catholic creed, through testimonies. The religious change in an indigenous community, Pantelhó (Chiapas), it has induced breaking bows of relationship and relatives. These changes in the social relations have been found in the testimonies inside this work.

Key words: identity and religious conversion, ethnic and religious diversity, social change.

\section{Introducción}

C hiapas es uno de los estados de la República Mexicana con mayor número de personas adscritas a religiones no católicas y diversidad de credos religiosos (De la Torre y Gutiérrez, 2007). ${ }^{2}$ Entre los municipios de Chiapas, Pantelhó no ha sido la excepción a este fenómeno de cambio social, lugar que se ha convertido en sede de nuevos credos religiosos no católicos, en sus inicios con un número incipiente de adeptos hasta alcanzar, aproximadamente, un tercio de la población de 5 y más años de edad que declaró adscribirse a alguna religión no católica, en el año 2000. Dada la importancia del fenómeno del cambio de 
adscripción religiosa en la sociedad, éste ha sido tema de interés de la antropología, la sociología, la historia, la política, la psicología, entre otras disciplinas, con la finalidad de comprender y analizar los cambios religiosos en el comportamiento humano y en las relaciones sociales.

En las investigaciones se reporta que debido a la diversidad religiosa, se han generado constantes cambios en la sociedad: disidencia, imbricación de diferencias políticas y religiosas, cambios en las creencias, principalmente en la cosmovisión de los pueblos, en las tradiciones, usos y costumbres, dejando de ser lo que habían sido antes religiosamente hablando. También se explica que la introducción de nuevas corrientes religiosas ha generado conflictos entre católicos y no católicos en algunos municipios del estado de Chiapas, principalmente en la zona de Los Altos: San Juan Chamula, Zinacantán y Chenalhó. En esos municipios se suscitaron contiendas en extremo violentas, donde los conversos fueron expulsados de sus hogares, además de otras razones, por practicar un credo religioso distinto al católico (Robledo, 1987; Rivera, et al., 2005; Garma, 2005: 34-35).

Los estudios sobre la diversidad religiosa, cambios y conflictos socio-religiosos en Chiapas son abundantes. Entre los autores que han prestado mayor atención a esta problemática están Rivera, Lisbona y García (2004; Rivera, et al., 2005), quienes clasificaron los niveles de agresión en los conflictos religiosos como: radicales, intermedios y de naturaleza intimidatoria. ${ }^{3}$ Explican asimismo que las contiendas se han ido generalizando hacia otros lugares de la entidad, aunque con variantes en el nivel de violencia pues en algunos casos sólo se limitan a ser agresiones verbales.

Esta situación de conflicto, junto al incremento constante de adeptos que han cambiado de adscripción religiosa e incluso de algunos que se han convertido, permite plantear la siguiente pregunta: si el ser evangélico acarrea dificultades en la vida comunitaria ipor qué cambiar?

En este trabajo queremos explicar que la incursión de religiones no católicas y el cambio religioso, a la vez que ha generado conflictos o desacuerdos en las comunidades, también han propiciado el mejoramiento de las condiciones de vida de algunos conversos cuyas nuevas opciones religiosas se presentaron como la posibilidad de encontrar otros caminos que le dieron sentido espiritual a la vida personal y familiar.

El objetivo de este trabajo es dar a conocer cómo ha sido el proceso de cambio religioso de católico a credos no católicos a través de testimonios de los implicados en el proceso, es decir, se pretende con la presentación de los diversos relatos ejemplificar el cambio religioso en la población que habita la cabecera municipal de Pantelhó, Chiapas; e indagar las razones personales que el sujeto de cambio explica al decidir optar por otra religión y, en su caso, ser converso.

Los testimonios se transcriben de manera textual y en un modo coloquial de habla de la región. Algunos entrevistados en el momento de relatar sus experiencias de haber optado por otro credo religioso, se mostraron un tanto emocionados y conmovidos por los "milagros", según explican, que Dios les concedió. Estas personas dijeron estar completamente entregadas a Dios y a su iglesia debido al cambio favorable que observaron en su vida personal y familiar; otros dan cuenta de situaciones críticas (individuales y familiares) por las que estaban pasando antes del cambio de adscripción, lo que llevó en unos casos a un cuestionamiento de la fe y, en otros, a un acercamiento a otras opciones religiosas.

La información aquí presentada es resultado de entrevistas a profundidad dirigidas a conversos miembros de las diferentes iglesias no católicas (adventista del Séptimo Día, Sólo Cristo Salva, de Dios Evangelio Completo, Nueva Esperanza y Jesucristo de los Santos de los Últimos Días), a líderes religiosos y a católicos; de éstos últimos, se entrevistó a personas que fueron identificadas por gente de la comunidad como "acti- 
vas" por asumir cargos religiosos y ser más "leales” al catolicismo. $^{4}$

\section{La comunidad de estudio ${ }^{5}$}

El municipio de Pantelhó se ubica en las montañas del norte de Chiapas. De acuerdo al II Conteo de población y vivienda, 2005, cuenta con 19,228 habitantes, de los cuales $49.7 \%$ son hombres y $50.3 \%$ son mujeres, cuyo índice de masculinidad es de 98.99 hombres por cada 100 mujeres. El grupo de edad de 0 a 19 años representa $52.8 \%$ de la población total del municipio, lo que significa que es predominantemente joven, cuya edad media municipal es de 16 años (INEGI, 2005).

La población del municipio está distribuida en 123 localidades siendo la mayoría de éstas menores a 999 habitantes, así, 56.7\% de los residentes vive en 121 localidades pequeñas y dispersas. Sólo dos localidades tienen más de mil habitantes, donde se concentra 43.3\% de la población total del municipio: Pantelhó cabecera municipal con 6,387 y Aurora Esquipulas con 1,933 (INEGI, 2005).

La población de 5 y más años de edad en el municipio es de 14,624 personas, de éstas 13,509 dijeron hablar una lengua indígena, lo que representa 92.4\%, a diferencia de $7.6 \%$ que indicó no hablar legua indígena. Las lenguas indígenas que se hablan en el municipio son: tzeltal (53.0\%), tzotzil (46.9\%), y un hablante de chol, además de tres personas que no especificaron la lengua indígena que hablan (INEGI, 2005).

Un alto porcentaje de los hablantes de lengua indígena no habla español (45.3\%), esta situación de monolingüismo se presenta principalmente en personas adultas y en las muy jóvenes que viven en localidades pequeñas y distantes por lo que casi no tienen contacto con la cabecera municipal. De la población monolingüe en lengua indígena se registra que es mayor el porcentaje de mujeres indígenas con esta condición de habla (INEGI, 2005).

Los que declararon no hablar lengua indígena son conocidos como mestizos, aunque algunos, principalmente adultos, la hablan, dado que es necesario para interactuar con los indígenas con quienes se relacionan socialmente ya sea en el ámbito económico, político o religioso. Los mestizos de edades jóvenes, por lo común, no se interesan en hablar lengua indígena, a menos que el sustento familiar provenga del comercio, es decir, compra y venta de café, maíz, fríjol, ganado, aves de corral, o en su caso, que tengan algún negocio como farmacia, abarrotes, tienda de ropa, etcétera, situación que los obliga aprender una lengua indígena.

A partir de la observación de campo y de la revisión censal podemos decir que existe diversidad étnica en el municipio y que la relación demográfica de estos grupos es distinta en la cabecera municipal y en las localidades; así, en la cabecera municipal habita un grupo considerable de tzotziles, de mestizos y un pequeño número de tzeltales; en cambio, en las localidades del municipio de Pantelhó la población es mayoritariamente indígena en las que interactúan tzotziles, tzeltales y un bajo porcentaje de mestizos.

La cabecera municipal alberga a 6,387 personas, que representan $33.22 \%$ del total de la población del municipio, y está dividida por barrios, siendo los siguientes: La Piedad, El Reparo, Los Naranjos, San Ramón, Santa Cruz, Guadalupe, San Antonio y Centro (Köhler, 2007).

En la cabecera municipal de Pantelhó se puede observar que las personas que cambian de adscripción religiosa viven principalmente en los barrios con mayor presencia indígena: Guadalupe, San Antonio y Santa Cruz, y en los alrededores del pueblo. La mayoría de los habitantes que vive en el centro, principalmente mestizos, no presentan este comportamiento, los propios católicos aseguran que "no son fáciles de convencer" y que el catolicismo se encuentra "fuerte"; en ese sector son pocos los que cambiaron de religión y no es un grupo representativo, aunque con la reciente construcción de la iglesia de los Santos de los Últimos Días es factible que este patrón cambie por su ubicación en el centro 
(Pantelhó, Chiapas, julio de 2006).

\section{Credos religiosos en Pantelhó, Chiapas ${ }^{6}$}

En la cabecera municipal es notorio el incremento de adeptos a religiones no católicas, de este modo surge la interrogante: ipor qué en Pantelhó, pueblo de costumbres y tradiciones, por la pluriculturalidad que coexiste en este municipio, donde año con año se celebran las fiestas de los patronos con anuncios, ferias y carnavales en las que participan los católicos del pueblo (indígenas y mestizos), de pronto, por alguna razón, están renunciando a esas prácticas para formar otros grupos religiosos, creándose una nueva identidad que desiste del catolicismo? De esta mane$\mathrm{ra}$, familias que por generaciones se han considerado católicas, actualmente forman parte de congregaciones no católicas.

La información que se presenta en este trabajo se basa en testimonios de conversos, de miembros de las iglesias y de practicantes católicos y no católicos; hombres y mujeres de edad adulta (de 30 a 80 años), dedicados a labores del campo, del hogar, al comercio y servicios, de quienes omitimos su nombre respetando el anonimato solicitado por los entrevistados.

En la cabecera municipal de Pantelhó se practican cinco credos religiosos: católico, adventista del Séptimo Día, pentecostal, presbiteriano y mormón. La religión católica sigue siendo mayoritaria, y debido a la diversidad étnica que existe en la cabecera municipal ésta se dividió en dos grupos: la católica practicada por mestizos y la católica "tradicional" practicada por indígenas tzotziles o católicos de la costumbre; así, anualmente durante las festividades de los santos patronos más importantes del pueblo, Jesús de la Buena Esperanza el 6 de agosto y Santa Catarina el 25 de noviembre, ambos grupos realizan los festejos en forma paralela y por separado, cada uno a la manera acostumbrada de hacerlo.

Esta separación étnica, dicotómica, entre indígena y mestizo, no sólo se presenta en la cuestión religiosa, sino también se puede observar en la descripción histórica de la fundación del pueblo de Pantelhó en la que tanto indígenas como mestizos argumentan ser los originarios y los que tienen la verdadera versión del mito de fundación (véase Brown, 2005).

Cabe aclarar que en la cabecera municipal de Pantelhó los practicantes de la religión católica de la costumbre buscan con sus celebraciones conservar la música y la danza heredada de sus ancestros, quienes veneraban los elementos de la naturaleza, debido a ello realizan sus ceremonias y sus fiestas patronales de manera distinta a los católicos mestizos y se identifican también con el nombre de tradicionalistas o de la costumbre; así, la religión "tradicional", en este caso, es la religión católica practicada por indígenas pero con expresiones religiosas que no son exclusivamente occidentales, sino que conservan aspectos de rituales mayas, prácticas que año con año son expresadas por "musiqueros y bailarines", como ellos los llaman, quienes luchan por conservar su cultura materna.

Durante la segunda mitad del siglo XX, comenzaron a ingresar otras corrientes de pensamiento religioso. La primera corriente religiosa no católica en Pantelhó fue la doctrina adventista del Séptimo Día que se introdujo mediante medios masivos de comunicación, en este caso, a través de un programa de radio, de una estación radiofónica de Guatemala que se sintonizaba en el municipio? ${ }^{?}$

Según explica un pastor de la iglesia adventista del Séptimo Día, hubo personas de la localidad que se comunicaron a la radiodifusora de Guatemala por medio de correo solicitando estudios bíblicos y así pedir apoyo para que se fundara una iglesia en el pueblo, la radiodifusora les notificó que en México había iglesias de este tipo y enviaron a Pantelhó a dos pastores para que predicaran (Pantelhó, Chiapas, julio de 2006). Las primeras personas que escucharon estas predicaciones, principalmente del barrio de Santa Cruz se dieron a la tarea de difundir el mensaje al establecer el primer 
templo no católico en el pueblo. Actualmente existen dos templos adventistas del Séptimo Día que se encuentran ubicados en el barrio de Santa Cruz, a uno asisten tzotziles y mestizos, en el otro participan únicamente tzotziles.

La segunda iglesia se fundó por los años de 1988-1989: la iglesia Sólo Cristo Salva del grupo religioso pentecostal. Ésta surgió producto de una ruptura entre líderes adventistas cuyos desacuerdos se basaron en la diferente interpretación de la Biblia y la rigidez en la práctica del culto, provocando la separación de un líder adventista y fundador del grupo pentecostal de la iglesia Sólo Cristo Salva, junto con la ayuda de un familiar que vivía en la ciudad de Tuxtla Gutiérrez y practicaba esa religión. En los primeros años el culto se realizaba en casa del fundador y por el año de 1994 se construyó el templo en el barrio El Reparo. A esta iglesia pentecostal acuden tzotziles y algunos mestizos.

La segunda iglesia de culto pentecostal denominada Dios Evangelio Completo se fundó cerca del año de 1995 por indígenas tzeltales provenientes de la localidad El Roblar municipio de Pantelhó. En aquel lugar ya se contaba con una iglesia pentecostal y al arribar a la cabecera municipal las personas llevaron el culto, tiempo después sus fundadores emigraron a tierras nacionales.

En sus inicios el número aproximado de miembros de la iglesia de Dios Evangelio Completo fue alrededor de 30 personas adultas y 20 más entre niños y jóvenes tzeltales. El templo está ubicado en el barrio de Guadalupe. Su doctrina se basa en la declaración de fe, inspiración de la Biblia, creencia en el padre, hijo y el espíritu santo, creencia en la sanidad por medio de la oración y el poder del espíritu santo para lograr hablar en lenguas (glosolalia), sin embargo, en esta iglesia aún no hay alguien que tenga esos dones.

La iglesia presbiteriana Nueva Esperanza se fundó en el año de 1987, ésta fue organizada por familias tzeltales provenientes de la localidad Santa Lucia, municipio de Pantelhó, que migraron a la cabecera municipal. La labor proselitista que realizó la iglesia presbiteriana, situada en el barrio de Guadalupe, logró congregar alrededor de 40 familias. La mayor parte de las personas que asisten al templo presbiteriano son tzeltales y aunque en la actualidad también asisten tzotziles las predicaciones que se dan en cada culto son en lengua tzeltal.

Por último, la iglesia de Jesucristo de los Santos de los Últimos Días (mormón) se estableció en el año de 2006. De acuerdo a la información de un elder, se pensaba construir esta iglesia en la comunidad El Porvenir municipio de Pantelhó, pero la gente se opuso a ello. Después de analizar el área decidieron instalarse en la cabecera municipal donde no tuvieron problemas; llegaron a predicar e hicieron labor proselitista de casa en casa. El templo de la iglesia de Jesucristo de los Santos de los Últimos Días está ubicado en el centro de la cabecera municipal. La mayor parte de la gente que asiste al templo es tzotzil y los cultos se practican en esa lengua. Además acuden al templo algunos tzeltales, pocos mestizos y también personas de las localidades circunvecinas (Pantelhó, Chiapas, julio de 2006).

En síntesis, el año 2006, en la cabecera municipal de Pantelhó, había seis templos no católicos: dos de ellos del culto pentecostal, uno presbiteriano, dos adventistas del Séptimo Día y uno de la Iglesia de Jesucristo de los Santos de Los Últimos Días. Por lo común, según observación de campo, en todos ellos el culto se realiza en lengua indígena.

El registro censal que da cuenta de las primeras incursiones de religiones no católicas en el municipio de Pantelhó es el del año de 1960, en el cual se registró un número incipiente de protestantes (según clasificación censal), 27 personas, a diferencia de las 4,806 personas que declararon ser católicas, además de 131 que no especificaron credo religioso y 2 que se declararon sin religión (SIC, 1963).

En décadas posteriores el número de adeptos a religiones no católicas se fue incrementando como también la diversidad de denominaciones. La comunidad evangélica comenzó a crecer. Se notó un aumento 
de conversos, no sólo de indígenas, que en un principio eran la mayoría, sino también de mestizos de bajos recursos.

Según datos del XII Censo General de Población y Vivienda del año 2000, en el municipio existía una población de 12,281 personas de 5 y más años de edad, de este número el porcentaje de personas que declararon ser católicas fue de 53.3\%, la suma porcentual de no católicos representó 30.7\%, mientras que 10.2\% se declaró sin religión y 5.8\% no especificó credo religioso (INEGI, 2000).

Las diferencias por sexo en las adscripciones religiosas censales son poco significativas; entre los católicos y los que se declararon sin religión el dato porcentual fue ligeramente mayor en los hombres que en las mujeres; $y$ viceversa, en las religiones no católicas fue ligeramente mayor el porcentaje de mujeres que de hombres.

Población de 5 y más años de edad por sexo según religión.

Pantelhó, Chiapas, 2000

\begin{tabular}{|l||c|c||c|c||c|c||}
\hline \multicolumn{1}{|c|}{ Religión } & \multicolumn{2}{c|}{ Total } & \multicolumn{2}{c|}{ Hombres } & \multicolumn{2}{c||}{ Mujeres } \\
\hline \hline & Número & $\%$ & Número & $\%$ & Número & $\%$ \\
\hline \hline Total & 12,281 & 100 & 6,114 & 100 & 6,167 & 100 \\
\hline \hline Católica & 6,551 & 53.3 & 3,291 & 53.8 & 3,206 & 52.9 \\
\hline \hline Históricas & 1,982 & 16.1 & 952 & 15.6 & 1,030 & 16.7 \\
\hline \hline Pentecostales y neopentecostales & 1,241 & 10.1 & 609 & 10.0 & 632 & 10.2 \\
\hline \hline Otras evangélicas & 166 & 1.4 & 82 & 1.3 & 84 & 1.4 \\
\hline Adventistas del Séptimo Día & 329 & 2.7 & 159 & 2.6 & 170 & 2.8 \\
\hline \hline $\begin{array}{l}\text { Iglesia de Jesucristo de los Santos de los } \\
\text { Últimos Días (mormones) }\end{array}$ & 36 & 0.3 & 20 & 0.3 & 16 & 0.3 \\
\hline \hline Testigos de Jehová & 11 & 0.1 & 8 & 0.1 & 3 & 0.0 \\
\hline Otras religiones & 1 & 0.0 & 0 & 0.0 & 1 & 0.0 \\
\hline Sin religión & 1,248 & 10.2 & 657 & 10.7 & 591 & 9.6 \\
\hline \hline No especificado & 716 & 5.8 & 336 & 5.5 & 380 & 6.2 \\
\hline
\end{tabular}

Fuente: INEGI. XII Censo general de población y vivienda 2000. http://www.inegi.gob.mx. 
El cambio de adscripción religiosa es un fenómeno relacionado con la identidad individual y como tal es cambiante, es la aceptación o rechazo de pertenencia a algún grupo religioso, fenómeno que cobra importancia por la diversidad de opciones religiosas que se observan en las regiones étnicas y por el impacto que tiene este tipo de cambio social en naciones pluriétnicas como la mexicana.

La adscripción religiosa se entiende así como el elemento de verificación y refutación individual a través del cual el individuo se asume o no como católico, adventista del Séptimo Día, presbiteriano, u otra opción religiosa (Villasana, 2002: 40).

El cambio de adscripción religiosa difiere entre las personas, según la situación y el contexto en el que viven ya que los posibles conversos no siguen el mismo patrón de cambio. Además se debe tener una o más razones para cambiar de opción religiosa, razones que pueden ser distintas en cada individuo, es decir, multicausal. En cambio la conversión religiosa ha sido definida como un proceso y un cambio de identidad que trasciende lo individual, como apunta Molinari: "La conversión no sólo afecta a la vida del converso, sino que tiene además consecuencias y repercusiones en su comunidad" (1998: 198). Es así un proceso de cambio interno, individual, que posteriormente se transforma en un proceso de transición social y culmina en el cambio de las prácticas religiosas que se verán reflejadas en la vida del adepto y en las relaciones sociales de éste.

La conversión marca una "trasformación en la vida del individuo" (Garma, 1988: 56), sufre una reestructuración en su conducta frente a nuevos valores religiosos que tienen que ver con un cambio espiritual y llevar una vida apegada a las normas del cristianismo desde la perspectiva del protestantismo. Como crisis de identidad, el proceso de conversión religiosa replantea en el individuo su ser religioso (López, 1990); significa dejar de ser lo que había sido antes en el contexto religioso.
El individuo, al convertirse de católico a no católico, cuestiona las festividades religiosas católicas aduciendo que son prácticas paganas y explica que al "entregarse en cuerpo y alma a Dios", incorpora todas las enseñanzas de su doctrina y demuestra un cambio espiritual, interno, de identidad. En palabras de Fabre:

...el sujeto social converso participa activamente en la reformulación de su quehacer y en la concepción del mundo; se encuentra inmerso en la búsqueda permanente de un orden distinto, de transición entre lo que Desea Ser y lo que es efectivamente. En este sentido, la conversión religiosa se traduce en una vía de cambio, en un proceso que va de un pasado-presente deteriorado hacia un presente-futuro prometedor; de construcción de identidad a través de la religiosidad que adoptó (2001:278).

\section{Razones del cambio de adscripción religiosa y conversión}

Todas las personas que se han adscrito a otra religión o que se han convertido argumentan diferentes razones de cambio, mostrando con ello que el cambio de adscripción religiosa y la posible conversión es multicausal. No obstante, en los testimonios se explica un mismo propósito: mejorar la forma de vida en lo espiritual, en lo material y en lo social.

En los testimonios, el factor de cambio más visible fue el económico, seguido de los problemas intrafamiliares de violencia debida al alcoholismo de alguno de los miembros de la familia. Otro factor mencionado fue el relacionado con los problemas de salud y la búsqueda de su curación, así también el papel que ha jugado la importante labor de convencimiento en momentos de crisis personal y familiar que realizan las iglesias evangélicas, es decir, el proselitismo religioso.

Respecto al factor económico, los testimonios hacen énfasis en la situación de carencia. En los templos evangélicos se puede observar, incluso, que el mayor número 
de personas que se congregan son familias de bajos recursos, quienes acuden para estrechar las relaciones de apoyo y solidaridad. Así, por ejemplo, un pastor de la iglesia pentecostal y otro de la iglesia adventista del Séptimo Día comentan al respecto que...

Las personas que se convierten con más facilidad son de bajos recursos porque enfrentan muchos problemas, (Hombre mestizo de 36 años. Pastor de la iglesia pentecostal. Pantelhó, Chiapas, julio de 2006).

La gente humilde es la que escucha más rápido la palabra de Dios, ipor qué?, por necesidad, (Hombre tzotzil de 35 años, transportista o chofer. Pastor de la iglesia adventista del Séptimo Día. Pantelhó, Chiapas, julio de 2006).

La impotencia de no poder solucionar problemas de la vida cotidiana hace que el hombre busque un acercamiento divino y un cambio en su estilo de vida. Circunstancias como la pobreza, el alcoholismo y la enfermedad provocan que el individuo se torne más sensible cuando es evangelizado y es más susceptible a la invitación proselitista, a las prácticas religiosas no católicas, ya que se percata que en las iglesias no católicas las personas son un tanto solidarias con sus semejantes como mencionan los pastores de los templos evangélicos en algunos testimonios:

Cuando comenzó todo esto [la introducción de la religión evangélica en Pantelhó] salíamos a evangelizar de casa en casa, algunos no querían escuchar, pero con el tiempo mucha gente cambió. Evangelizamos familias tanto indígenas como mestizos. Nosotros hemos cambiado mucha gente pero verdaderamente perdidos en los vicios. Así como mira usted que hay personas tiradas en las calles por causa de los vicios, así eran esas personas. Ya ahora icómo andan esas personas? Ya andan bien vestiditos, montados en sus buenas bestias. Han cambiado. Bien calzados cuando en ese tiempo ni a eso llegaban, han cambiado eso es lo que les ha gustado a los demás es por eso que mucha gente se da cuenta y se cambian de religión (Hombre mestizo de 63 años, cafeticultor. Pastor de la iglesia adventista del Séptimo Día. Pantelhó, Chiapas, julio de 2006).

Pero aparte de eso la gente cambia, en el caso de los indígenas tzotziles porque ven, que bueno, más que nada si hay un hermano que necesita ayuda o está enfermo le llevamos una ofrenda, lo que la gente quiere dar ya sea maíz o de más cosas de comida. Es donde muchos lo ven, es diferente al católico (Hombre tzotzil de 35 años, transportista o chofer. Pastor de la iglesia adventista del Séptimo Día. Pantelhó, Chiapas, julio de 2006).

Nosotros apoyamos a nuestros hermanos económica y moralmente. Hay ocasiones que hay un enfermo y que tienen que internarlo y no tiene dinero, entonces nosotros nos reunimos, informamos a la iglesia y ya entre todos reunimos una ofrenda, una ofrenda que le llamamos "ofrenda de amor" y ya mandamos a alguien representando a la iglesia o voy yo acompañado de la directiva, vamos a visitarlo y entregarle la ofrenda, y no se queda ahí. Después se les da una despensa y no sólo lo hacemos con un miembro de la iglesia, lo hacemos también, digamos, con el vecino. Así también se apoyan a mujeres solas que tienen hijos pequeños o ya sus hijos la abandonaron, entonces las apoyamos, (Hombre mestizo de 36 años. Pastor de la iglesia pentecostal. Pantelhó, Chiapas, julio de 2006).

Aunque el pastor adventista del Séptimo Día no mencionó dentro de la entrevista directamente que la gente de bajos recursos se adscribe con mayor facilidad a religiones no católicas, lo dejó entrever en algún momento de su relato cuando mencionó a las "ofrendas" como un medio a través del cual se reúne dinero que sirve para ayudar a los conversos.

La "ofrenda" se da cada culto. El diezmo ya se da 
cuando alguien ya tiene un trabajo bueno, ya fijo, hasta eso lo que nazca de su corazón dar, porque La Biblia dice que hay que dar el diez por ciento, pero eso no debe ser. Por eso no obligamos a que den, porque hay mucha gente pobre que no lo puede dar y ique se les obligue!, es mejor voluntariamente; dos cincuenta, tres, cinco pesos (Hombre mestizo de 63 años, cafeticultor. Pastor de la iglesia adventista del Séptimo Día. Pantelhó, Chiapas, julio de 2006).

En esta entrevista podemos notar cómo el pastor adapta el sistema de "ofrenda" de tal modo que no se perjudique a los conversos debido a que la mayoría son de bajos recursos. Algunos católicos también comentan que las personas se cambian de religión porque reciben ayuda económica de las congregaciones no católicas. A propósito de ello un comentario de una señora católica destaca la discrepancia de los católicos con el ingreso de otras religiones y cómo esas estrategias de apoyo son funcionales para atraer adeptos:

Antes de los Monterrosa [adventistas del Séptimo Día] ya habían tratado de evangelizar otras persona por ahí de 1950. Aquí vivía René Cancino, los hermanos de él vinieron aquí a visitarlo o estarse aquí un tiempo. No sé muy bien, pero ellos quisieron evangelizar, pero quien sabe cómo fue su modo que rápido se juntó la gente indígena y los corrieron del pueblo. Yo salí del pueblo como 15 años, nos fuimos como en 1958. Ya cuando regresamos fue que me entero que había evangélicos aquí, un templo que había por allá arriba, pero casi no se sabía, estaban como más escondiditos, pero ahora ya tienen sus formas ya son más listos, son más abusados los atraen con regalos, (Mujer mestiza de 60 años, dedicada al hogar y al comercio. Católica. Pantelhó, Chiapas, junio de 2006).

Diversos testimonios dan cuenta de cómo la oferta de recursos, por parte de los grupos no católicos, es un factor que propicia el cambio de adscripción y, en su caso, la conversión religiosa en el municipio de Pantelhó. Tal es el caso de evangelización que está efectuando la iglesia de Jesucristo de los Santos de los Últimos Días. Durante el trabajo de campo se observó la presencia de dos camionetas de las cuales bajaban bolsas de despensa y utensilios de cocina que eran destinados a los habitantes del municipio, en su mayoría tzotziles. Así mismo, algunas personas comentaron acerca de la construcción del templo, para la cual contrataron a muchos trabajadores con sueldos muy altos, casi el doble de lo que acostumbran a ganar en estas mismas circunstancias, debido a que los mormones han logrado la conversión de indígenas tzotziles. Éstas son estrategias que usan las religiones no católicas para ganar adeptos y funcionan bastante bien.

De acuerdo a la información recabada en la cabecera municipal de Pantelhó, otra de las causas que origina el cambio religioso se presenta en personas que tienen problemas matrimoniales, en la mayoría de los casos provocados por la ingesta excesiva de alcohol por parte del esposo, aunada a la actitud machista que presumen los hombres de ese municipio, lo que culmina en el maltrato intrafamiliar. Así se muestra en los siguientes testimonios de adventistas del Séptimo Día y pentecostal:

Tengo 6 año cambie de religión porque antes yo fui católica, pero sufrí mucho. Llegaba aquí mi marido, es puro tomar cada sábado o domingo, no quiere dar dinero para comer, hay veces me pegaba y lo miran mis hijos. Pero no tengo donde ir, pero gracias a Dios vino mi primo a predicar la palabra. Primero mi marido no quiso escuchar, se enojaba. Yo luego entré porque ahí es mejor, poco a poco mi esposo lo escuchó, también mi primo llegó al templo con vergüenza, los dos estamos con Dios. Hora él lo mira mal todo, lo que hacía antes lo mira sus compañeros. Dice "pobre", así como cuando es carnaval es puro tomar, puro borrachera, así no quiere Dios.

Mi esposo es más tranquilo ya no regaña, ya no 
toma trago, ya no sale día sábado o domingo. Vamos los días sábado al templo a las 10 de la mañana y en la tarde. Es mejor, así estamos con Dios, (Mujer tzotzil de 33 años, dedicada al hogar. Adventista del Séptimo Día. Pantelhó, Chiapas, julio de 2006).

Tiene 10-11 años que cambié de religión porque en la religión católica no se lleva como es. La verdá yo me acuerdo bien, no te echo mentiras, que en los días de la fiesta de Santa Catarina y de Jesús de la Buena Esperanza, caso iba yo por ir a rezar o siquiera entrar en la iglesia. Bajaba yo al parque pero a buscar donde había trago, buscar los amigos para echarse unos tragos. Bajaba yo bien vestidito. Al rato ya venía yo todo cochino, venía yo a maltratar mi mujer. Mis hijos se escondían cuando venía yo, en lugar que salieran a verme, me tenían miedo. Oílo que necesidad iverdá? Pero así es mi hermano, cuando no se quiere dar uno cuenta de la verdá, porque el trago es el diablo que te está tentado y si no se acerca uno a Dios no se da uno cuenta. Así míralo. Pero caso sólo en las fiestas tomaba yo pue: Cada que se podía, si es posible semanalmente. Acaba uno mucho dinero por el vicio. Si me pedía dinero mi mujer o mis hijos, no había, pero para la botella eso sí. Era yo mujeriego, miraba yo una muchacha empezaba yo a molestarla a ver si había chance. siendo que tengo mi mujer. Esa vida que llevaba yo era el camino del mal, pero yo lo miraba yo que está bien, pero después vino las consecuencias, empezaron los pleitos con mi mujer bien duros, me iba yo a trabajar a mi terreno temprano, ya ni me amarraba mi almuerzo mi mujer. Una de tantas, como era mucho lo que le hacía yo mi muje,r me dejó, se fue ontá su mamá. Ahí fue donde empecé a reaccionar. Le fui a pedir perdón, pero no quería regresar, ni mis hijos me dejaba mirarlos. Después ella entró a la religión por una su comadre. Luego entró de que se fue, de que me dejó como a la semana. De ahí vino mi compadre junto con mi comadre a hablarme que estaba mal lo que estaba yo haciendo, que pensara yo en mi familia.
Y así fue que regresó mi mujer con la condición de que yo cambiara de religión y yo, como también ya quería yo cambiar, pues entré, hasta hoy fecha. Despuesito entraron mis suegros, después convencí a dos de mis hermanos, luego mis papás. Mira orita la verdá vivo feliz, contento. Poco a poco fui componiendo mi casita, vivimos en paz con la bendición de Dios, (Hombre mestizo de 36 años, campesino y comerciante de café. Pentecostal. Pantelhó, Chiapas, julio de 2006).

Tiene 6 año cambié religión, sólo así, de mi pensamiento nomás. Lo miro el católico es puro trago, es por eso mejor me voy a cambiar. Mi hijo tiene 15 años es cristiano, primero me enojé, ¿caso le hablo mi hijo?, después mi mujer empezó a ir, pero ahí ya no estoy enojado, le doy permiso va ir al templo. Después así nomás lo pensé y mejor me cambio aquí es mejor, no que el católico es puro tomar trago, voy a quedar tirado en la calle y voy acabar mi dinero por eso es mejor vengo aquí, (Hombre tzotzil de 61 años, campesino. Adventista del Séptimo Día. Pantelhó, Chiapas, julio de 2006).

En estos casos se puede ver que tanto el problema intrafamiliar como la ingesta excesiva de alcohol fueron factores que incidieron en estas familias para cambiar de religión. Como estos testimonios hay muchos que narran los conversos de los diferentes templos. Los mismos católicos opinan acerca de esos casos criticando la actitud de las personas, y mencionan: "No es fuerza cambiar de religión para dejar de beber, hay que tener fuerza de voluntad y encomendarse a Dios". "Ya está uno grande para hacer esas locuras, yo quería yo dejar de tomar entré al grupo Alcohólicos Anónimos, pero no por eso me fui a meter ahí" (Católicos, Pantelhó, Chiapas, julio de 2006).

Cuando un matrimonio vive una situación de esa magnitud, las personas se encuentran vulnerables a la conversión. Especialmente si están siendo evangelizadas, la predicación va en el sentido de la unión 
familiar. Al hablar sobre este tema adoptan una actitud de reflexión y sienten esa necesidad de estar con Dios para solucionar sus problemas y poder sobrepasar esos infortunios económicos, de salud, de violencia intrafamiliar, creando un estado de conformismo, pues su creencia y su fe es tan profunda que toda actividad que realizan en su vida la atribuyen a Dios.

Hubo personas que cambiaron de religión por su propia convicción y por desacuerdo con la forma de interpretar el rito católico; son personas que han recibido todos los sacramentos de la iglesia católica pero que encuentran un sentido más profundo de su creencia y su fe en otras religiones. Como es el caso del ahora pastor adventista del Séptimo Día quien relata ampliamente su experiencia; en el testimonio se observa cómo la conversión religiosa es un proceso largo de reflexión no mecánico.

Yo era católico, yo estuve como tres años de catequista, tenía como 18 años, empezamos a leer la Biblia, empezamos a conocer. Yo cambié de religión por el motivo de que el sacerdote a veces no predica completamente como debe de ser la palabra de Dios. Ellos utilizan un libro que se llama misal, en ese misal ya viene escogido especialmente lo que va a predicar. Más que nada no es completo lo que es la Biblia, siempre buscan como quieren ellos, por esa razón yo estuve estudiando parejo la Biblia, fue donde encontré detalles más favorables para la gente, más favorable hacía Dios, más que nada. Es por ésta razón yo estuve haciendo preguntas hacía los sacerdotes ipor qué no predican esto?, y ipor qué esta parte si?, y ipor qué esta no?

Entonces me decían: "es que esta parte es para los protestantes y ésta es para los católicos". Entonces dividían, pero la Santa Biblia son cosas de Dios, es una, entonces me decían: "es que si predico esto me van a correr y al final no me van a permitir a la gente". Yo le dije, "no, mira padre, si usted predica la palabra de Dios yo creo que Dios le va a ayudar porque está usted predicando la verdad no es mentira". Dice: "No, no se puede".

Así hemos discutido un poquito, con las discusiones de pleito de lo que es discusiones de Biblia "ipor qué aquí sí?, ¿ipor qué aquí no?, ipor qué, pues?”. ”No, que no se puede". Entonces ahí vi la diferencia, uno.

El otro también me doy cuenta como dice el padre, el padre le decimos su nombre. Yo platiqué también en una ocasión con el padre Juan Carlos que vino de la ciudad de México, le dije: "Mira padre, yo quería preguntarle una cosa. Aquí dice en la Biblia: no llamareis padre de nombre a un hombre igual que usted. No, no mellame padre, somos hermanos, es mejor que nos decimos hermanos porque yo no soy el padre, así lo dice la Biblia". Todos estos detalles los fui estudiando y vi muchas cosas, la diferencia. Otra de las cosas. No es por criticar a la iglesia católica por creer en su ídolos, sino que la creencia de ellos sinceramente la Biblia no lo permite, lo dice en el salmo 115 , lo dice claro que los ídolos tienen boca pero no hablan, tienen ojos pero no ven, hora sí que no se ve movimiento, entonces es ahí donde lo vi mal y tengo que buscar bien, tengo que ver donde me ubico, porque no puedo estar donde dicen puras mentiras, para qué, mejor sigo el camino que sea verdad, entonces, así cambié.

Anteriormente había un amigo mío, un primo más que nada, y él ya estaba en la iglesia de Séptimo Día. Entonces una ocasión nos pusimos a platicar las cosas de Dios, el era evangélico yo era catequista. Nos encontramos a platicar de que còmo predican ellos, entonces me dijo es así, me mostró unos textos y comencé a estudiar los textos que me dio porque hay dos partes, la iglesia y la creencia también, la iglesia dominical donde se asiste el día domingo comenzamos a platicarlo ipor qué el día domingo?, porque es así, entonces aquí dice el día sábado, el día sábado, el verdadero es día de Dios, que no se qué, pero el domingo es de Dios, entonces hay diferencia entre día sábado y día domingo. Entonces yo pedí unos texto porque quiero saber cuál es la realidad, cuál es el mejor, que 
si está escrito en la Biblia yo tengo que seguir lo que dice la Biblia, ¿verdad?. Entonces esa ocasión yo pedí texto de santo padre, y entonces yo preguntè sobre el día domingo. Entonces lo vi el día domingo, dice la Biblia que es el primer día de la semana. Entonces el día sábado dice la Biblia es día santo, sábado agradable a Dios y alabar a Dios y cantar a Dios dice san Lucas 4, dice también que Jesús es su costumbre predicar en toda las iglesia el día sábado. Entonces ahí fue la diferencia, entonces este no y este lo obedezco como hasta ahora, no, más que nada. Estoy desde hace 16 años en esta congregación por estas razones yo entré, (Hombre tzotzil de 35 años, transportista o chofer. Pastor de la iglesia adventista del Séptimo Día. Pantelhó, Chiapas, julio de 2006).

No sólo las personas desfavorecidas económicamente o con problemas de violencia intrafamiliar han cambiado de religión. Hay otros factores que inciden en ese cambio como los problemas de salud y la búsqueda de su solución y en este caso la práctica del don de sanidad divina juega un papel importante, como lo explica López para el caso de los pentecostales apostólicos:

El don de sanidad divina es un carisma que es ejercido únicamente para curar enfermedades del cuerpo. La curación física implica la curación de enfermedades orgánicas.

El que tiene el don de sanidad divina impone las manos y ora por la curación de la persona enferma. El que impone las manos es generalmente un ministro o algún miembro de la iglesia que tiene el don de sanidad. Muchas veces la imposición de manos se acompaña del ungimiento de aceite de olivo, (1990:67).

La situación socioeconómica empobrecida, la carencia de empleo, los bajos salarios provocan en muchas ocasiones no poder acceder a la educación, vivir en condiciones pésimas, no tener una alimentación sana y lo que es peor aún, enfrentar una enfermedad en la que el entorno familiar queda afectado.

Tanto los problemas de salud como la difícil forma de solucionarlos ante la pobreza son factores que inciden también en el cambio religioso. Existe el caso de conversión religiosa debida a que el individuo cambia por un milagro de salud que haya presenciado o por el alivio personal o de algún pariente, como lo relatan los siguientes testimonios:

Anteriormente yo era de la religión católica, pero en una ocasión mi esposa se puso muy enferma. Ya tenía como quince días en cama. Nosotros acostumbrábamos a curarnos con el curandero, él le reza el enfermo, también con mi familia le pedíamos a los santos, llegamos a la iglesia a rezar y a pedir por la salud de mi mujer. Como el curandero no pudo sanar mi mujer, intentamos con el doctor, le dio medicinas pero no se curó.

Ya había gastado mucho dinero, más con el curandero porque pide velas, trago y gallina y aparte hay que pagarle. Yo pensé que mi mujer se iba a morir, pero llegó mi sobrino a visitarnos a mi casa, él era de religión. Nos pusimos a platicar y le contéla situación en que se encontraba mi mujer. Él me propuso que traería a su pastor para que orara por mi mujer, sólo me pidió que tuviera fe y que creyera en Dios, yo acepte. Al día siguiente llegó el pastor con otros hermanos y oraron por mi mujer, así llegaron varios días y gracias a Dios se curó.

Es por eso que ahora toda mi familia acude al templo para alabar a Dios, por el pastor nos dijo que la religión católica no sirve porque no debemos hincarnos ante imágenes, por eso Dios no escuchó mis plegarias. Ahora en el templo sólo le rezamos a él porque nos escucha y no necesitamos de imágenes, (Hombre tzeltal de 45 años, campesino. Presbiteriano. Pantelhó, Chiapas, julio de 2006).

Antes de pertenecer a esta iglesia iba yo al templo católico, pero no vayas a creer que seguido me mirabas en la iglesia. Iba yo de vez en cuando, no había respeto, 
y las veces que iba, yo saliendo y estaba yo pensando en el mal, pero ahora que estoy con los hermanos, así como lo ves, vengo con mis dos hijitos, con mi esposa aunque sé que muchos me critican y me han dejado de hablar, peor que miran que en este templo hay hermanos tzotzileros y tzeltaleros. Sólo yo vengo de mestizo, no me da vergüenza porque yo ya he visto el poder de Dios de varias formas, yo ya he visto el poder de Dios.

Antes era yo grosero, peleonero, tomaba yo trago, me drogaba yo, andaba yo armado. A mí no me podían decir nada porque rápido me estaba yo peleando. Después que salía yo, según que a pasear, ya regresaba yo todo moreteado, hasta que un día quien sabe qué me pasó, yo pienso que Dios ya tenía preparado mi camino pero primero debía yo sufrir, comencé a torcer primero mis piernas icaso los podía yo mover?, después mis brazos, después se me torció mi cuello, apenas y me entendían lo que decía yo porque tenía yo dura mi boca, por esa enfermedad gaste como 80 mil pesos. Tuve esa enfermedad como tres años. Yo me dedico a la compra y venta de café, de caballos, ganado, de puercos, gallinas lo que caiga le hacemos, pues acabé con todo lo que tenía yo. Ya no tenía yo que comer, mi mujer y mis hijos sufrieron mucho, pero gracias a Dios mi mujer ahí estaba conmigo cuidándome, siendo pue que daba yo asco porque me tenían que asear: como mi boca lo tenía yo tiesa me escurría mucha saliva. Era una enfermedad muy fiera, me trataron todo tipo de doctores en San Cristóbal, Ocosingo, Tuxtla, y nada. Me decían que no tenía yo curación o me daban tratamientos caros, pero no me hacían efecto.

Como mi casa está aquí cerca del templo lo supieron los hermanos, casi toda la gente de aquí de mi rumbo lo sabía, así que un día se presentaron unos hermanos a querer predicarme me encabronaba yo. Así, dentro de mi mal les decía yo que si no me dejaban de chingar le iba yo a trabar un balazo. Cuando me empezó la necesidad le empecé a pedir a Dios que ya no aguantaba yo estar así, que si era su voluntad, que mejor me llevara de una ve. Ya nadie me quería prestar dinero, después llegó una hermana a platicar con mi mujer lo invitó que fuera al templo porque eso era lo que nos faltaba: acercarnos a Dio. Ya había yo acabado con armas, caballos acabé con todo.

Mi mujer llegó al templo yo sin saberlo, cuando ese día que fue, ya en la tardecita va llegando con el hermano Amilcar Cruz de Escárcega Campeche a visitarme. Me empezó a hablar, pue, bien bonito pero ya para eso Dios yo creo ya me había tocado mi corazón porque caso me opuso, al contrario, me quede quieto escuchando. Ahí, entonces, elevaron una oración. Dentro de mi también le pedía yo a Dios que tuviera misericordia. Pues como a lo cinco minutos lo sentí que mi cuello se empezó a destrabar. Sentía yo un hormigueo por mis brazos y mis piernas y medio los podía yo mover. Ahí mismo el pastor con voz fuerte decía "ahí está el poder de Dios". Me dijo que si me arrepentía yo de mis pecados, decía yo que sí, pero como no muy me entendía movía yo la cabeza diciendo que sí. Me dijo: "aceptas a Cristo". Le dije que si, y hasta la fecha, ya voy para cuatro años que vengo al templo. Míreme usted orita, ya estoy perfectamente, aunque pobres pero hay con Dios vamos saliendo. Mis hermanos no me hablaban, hasta uno que le debía me quitó mi casa. Hora estoy rentando una casita más aquí arriba.

Recién que me curé le presté ${ }^{8}$ un dinero mi mamá para que empezara yo a trabajar. Me lo negó, me mandó a decir un día con uno de mis hijos dio 20 mil pesos para mi curación, pero ahora que era yo evangélico pues hay que me dieran los hermanos, que me dieran esos locos. Pero ya en estos días nos hablamos, lo han visto como he cambiado, les predico a mis hermanos. Poco a poco unos ya han venido a escuchar, pero lo ven pues mi cambio, ya no soy el alocado de antes, no soy esa persona áspera con 
mi mujer, mis hijos, les compro lo que quieren. No que antes no había, venía y borracho a pegarle a mi mujer y mis hijos se escondían, en cambio hora me pueden dar las doce de la noche en la calle y no se preocupan, saben que voy a llegar tranquilo con algo en mis manos una su torta o algo. Así, poco a poco me he ido superando, ya pagué mis deudas, ya compré un mi terrenito y estoy ahorrando para empezar a construir y tener algo propio. Tengo una mi camionetita que me sirve para la chamba. A mi familia no le falta nada, mis hijos no les falta su leche, sus zapatos, ya estoy más al pendiente de mi familia, así, poco a poco con el poder de Dios bendito vamos saliendo, ${ }^{9}$ (Hombre mestizo de 32 años, comerciante de café y ganado. Pentecostal. Pantelhó, Chiapas, julio de 2006).

El cambio de adscripción religiosa asociado a sanar de manera milagrosa se ve muy a menudo en campañas evangélicas que realiza la religión pentecostal en distintos lugares de Chiapas. A dichas campañas se invitan predicadores de otros países o nacionales que se les atribuye el don de sanar, en la parte final del evento se reserva un momento para el acto de sanar a las personas que padezcan alguna enfermedad o tengan alguna discapacidad como ceguera o invalidez. El predicador eleva una oración junto con las personas que acuden al lugar y por último el predicador dice "en el nombre de Jesucristo esta noche declaro milagro", entonces todas las personas que pasaron para sanar algún padecimiento, puede ser individual o grupal, caen de espaldas en condición de desmayados y al levantarse se presume que su mal está curado.

Lo importante de esta idea es que al terminar con el acto de sanar, el predicador, después de realizar una oración y de cantar alguna a labanza, pide nuevamente que pasen las personas que quieran aceptar a Cristo, por supuesto, después de lo acontecido decenas de personas pasan a recibir a Cristo. A estos eventos de- dicados a buscar la cura de algún padecimiento asiste gente de diversos lugares y los que ya son evangélicos invitan a sus familiares, amigos o vecinos que aún no se convierten para que presencien todas las actividades que realizan esperando que al término de esa cruzada se convenzan y accedan a la conversión.

En la cabecera municipal de Pantelhó se realizan también este tipo de eventos organizados por la iglesia pentecostal Sólo Cristo Salva, aunque son menos espectaculares. Durante nuestro trabajo de campo observamos cómo algunas personas presuntamente inválidas que acudieron a uno de estos eventos, al participar en el acto de sanar se levantaron de su silla de ruedas. Casos como esos hacen que otras personas, aún católicas, tengan la curiosidad de saber si realmente estos acontecimientos son ciertos y poco a poco también acuden al templo.

Por último, hay quienes tienden a cambiar de religión para evadir cumplir algún cargo religioso católico, ya sea de regidores, alférez o priostes, y de este modo evitar realizar la organización de las fiestas patronales, o no participan en la organización del carnaval, pues estos festejos católicos implican un gasto considerable. Unos informantes católicos mencionaron que existen individuos que cambian de religión para evadir el cargo de capitán, quien es el encargado de realizar el anuncio de las festividades patronales, así como muchos de los "costumbreros" (católicos de la costumbre), cambian para no aceptar los cargos religiosos de alférez. El pastor de la iglesia adventista del Séptimo Día comentó al respecto:

Algunos cambian porque exigen pues, los tradicionales para tener cargo y se gasta mucho dinero en trago y sólo se emborracha es por eso mejor cambiar, así ya no te molestan al contrario hay ayuda, así es que solos se dan cuenta, (Hombre tzotzil de 35 años, transportista o chofer. Pastor de la iglesia adventista del Séptimo Día. Pantelhó, Chiapas, julio de 2006). La labor proselitista 
Desde otra perspectiva podemos situar este fenómeno de conversión religiosa en el plano proselitista. Es obvio que para adoptar una nueva religión primero hay que saber que existe, lo cual no presenta ningún problema por la labor proselitista que las iglesias no católicas efectúan ante la sociedad. Regularmente los conversos son invitados por las personas que salen a evangelizar de casa en casa o por un amigo, conocido o familiar, y otras veces son motivados por campañas masivas que organizan las iglesias. Al principio como no se tiene un templo, el pastor predica en la casa de la persona que está convenciendo, ésta a su vez convertida tendrá la misión de evangelizar a vecinos amigos y familiares.

Cuando se logra convertir a un grupo considerable es necesario construir un templo el cual se puede hacer con el dinero recolectado en las ofrendas y el diezmo de los fieles. En ocasiones uno de los conversos dona el terreno. En la construcción del templo colaboran todos los hombres que forman parte de la nueva iglesia. También se pueden formar nuevas congregaciones a partir de la ruptura, es decir, algunos templos presentan dificultades en su organización, discrepancias que provocan un cisma al interior de la congregación trayendo con esto la separación de una parte del grupo que posteriormente forma otra congregación.

En el municipio de Pantelhó cada grupo religioso no católico se organiza de manera diferente para realizar labor proselitista, en unas se observó una organización frágil y en otras una organización más sistemática. Las iglesias que realizan intensa labor proselitista son: adventista del Séptimo Día, pentecostal y la Iglesia de los Santos de los Últimos días. De estas iglesias las dos primeras no están bien organizadas, sólo las personas que desean salen a predicar, las cuales son pocas; por el contrario, el grupo mormón es el único que se organiza en forma bien estructurada y para difundir la religión en la comunidad los encargados de esta labor proselitista salen todos los días mañana y tarde acompañados en parejas para hacer visitas domiciliarias.

El proselitismo religioso juega un papel importante en la proliferación de adeptos a religiones no católicas. Vázquez comenta al respecto:

La aceptación de la labor proselitista generalmente es favorecida por presentarse asociada a actividades novedosas, ligadas a hechos milagrosos, en un ambiente animado por oraciones fervorosas, sanidad, glosolalia, don de profecía, donde se obtiene una paz inmensa, esperanza, un encuentro consigo mismo, una nueva oportunidad de restauración moral y social, entre otras manifestaciones espirituales, que por cierto, conforme pasa el tiempo resultan ser menos frecuentes y menos espectaculares, (Vázquez, 1999:159).

Es importante reiterar que la mayoría de las personas que cambian de religión son invitadas por un familiar converso o en proceso de conversión, como se observó en los testimonios presentados y puede ser el cónyuge, el hijo u otra parentela; en otros casos, el convencimiento se inicia a través de la visita de los predicadores a los hogares de los cuales se tiene conocimiento de algún problema familiar o de salud; sólo las personas que fueron precursoras de las nuevas religiones en Pantelhó, tuvieron trato directo con el pastor o con predicadores foráneos.

La actividad proselitista es muy intensa entre los grupos no católicos, no así entre los católicos. En Pantelhó nunca se ha visto que católicos salgan a predicar de casa en casa o realicen algún tipo de campaña proselitista entre la población, salvo la celebración de las fiestas patronales que ya están institucionalizadas; en cambio, las nuevas religiones tienen que hacerse de adeptos y difundir su doctrina a través de diversos medios, como es el caso del grupo mormón que por su reciente introducción a la comunidad está tratando de adscribir adeptos al gremio intensificando su labor proselitista de casa en casa y en la que literalmente 
tratan de llevar directo al templo al posible converso para formar parte de éste.

En esta labor de cambio de los evangélicos es imprescindible el uso de la Biblia, a excepción de los mormones quienes utilizan el Libro de Mormón. En los templos no católicos se aprecia la participación familiar, se observa una interacción entre el pastor y los fieles ejecutando alabanzas y oraciones. Si alguno de los creyentes faltara a su iglesia los miembros de ésta forman un comité junto con el pastor para visitarlo en su casa y ellos se encargan de proporcionarle ayuda moral y económica según sea su situación o de simplemente indagar los motivos por los cuales está faltando. Esta solidaridad se observa en la cabecera municipal de Pantelhó y es probable que a muchos les despierte la curiosidad por conocer esas nuevas prácticas religiosas.

Existen otros medios de difundir la religión, por ejemplo, se llevan a cabo campañas masivas donde el pastor predica y realiza alabanzas en el parque central del pueblo, aunado a esto, existe la difusión de la religión evangélica por medio de programas de televisión y radio transmitidos desde Tuxtla Gutiérrez, capital del estado, y de la ciudad de San Cristóbal de Las Casas, que se sintonizan en Pantelhó, además de la exhibición de películas cristianas y la distribución de música en medios magnéticos.

Así, las campañas proselitistas influyen en el cambio de adscripción religiosa, que favorece la adhesión de nuevos adeptos. Al pastor le corresponde formar el grupo evangélico, éste es enviado por sus superiores, ya sea a una cabecera municipal, comunidad o ciudad, pueden quienes? buscar un empleo y en el caso de la iglesia pentecostal el pastor comentó que normalmente están financiados. Por favor revisar este párrafo.

La labor proselitista del pastor tiene que comenzar con hacer amistad entre sus vecinos y predicar de casa en casa donde en ocasiones será rechazado; cuando observa que una persona muestra interés por escuchar la predicación continuará asistiendo hasta lograr su conversión.

En la familia la esposa es, por lo común, la que en un principio muestra interés por una religión diferente a la que practican. Según versión del pastor pentecostal, siempre que evangelizan la mujer es la que acepta la invitación para acudir a templos no católicos, aunque hay casos en que el hombre toma la iniciativa y esporádicamente son los jóvenes.

Una vez que observan que existe un interés de la persona por conocer aquella religión, el pastor o los grupos que evangelizan de casa en casa o algún familiar, se tornan persistentes y sus visitas son constantes para continuar evangelizando. Estos primeros acercamientos son en el hogar del futuro converso, posteriormente son invitados a asistir al templo, sin ser una obligación cambiar de religión al acudir o participar en los ritos que se realizan al interior de éstos, solamente llegan como espectadores. Usualmente los invitados terminan por convertirse, debido en parte al convencimiento y a la perseverancia de cuya fama gozan los evangelistas, pero también recordemos que existen causas profundas individuales previas al acercamiento del prosélito.

Luego de que un miembro de la familia pasa a formar parte de una iglesia evangélica, le corresponde a éste evangelizar a los integrantes de su hogar. Cuando la esposa es la primera en convertirse, el primero al que debe convencer es al esposo. Hay ocasiones en que el esposo se muestra razonable en cuanto a la decisión que ha tomado su esposa, no le molesta que escuche música y vea películas cristianas, no le prohíbe asistir al templo, lo que ocasiona que la esposa se sienta en confianza y poco a poco comience a inducirlo por el mismo camino.

Pero en otros casos el esposo no está de acuerdo, éste no permite que su mujer asista al templo, constantemente hay discusiones y surge el temor a las críticas que recibirá de amigos y personas cercanas a él, situación que afecta en el plano individual, sobre todo en un pueblo donde normalmente la mayoría de la gente se conoce. 
Según versión de los informantes, es aquí donde la mujer se muestra perseverante, ora todos los días, pide a Dios que su esposo también cambie, se comporta complaciente con el esposo y pone en práctica lo que aprende en el templo, es más tolerante con sus hijos, tiene que exponer que existe un cambio en su conducta que avale que su conversión es para bien de la familia, para que el esposo poco a poco se vaya convenciendo.

\section{Palabras finales}

El fenómeno social del cambio de adscripción religiosa y en su caso de conversión religiosa es multifactorial y heterogéneo, es decir, en los testimonios se observó que el cambio de adscripción religiosa se debió a múltiples factores: enfermedad, económicos, de cambio cultural y a la importante labor proselitista en el entorno comunitario, entre otros, mostrando con ello la multicausalidad del fenómeno de conversión religiosa.

En las entrevistas se expresaron opiniones de diversa índole, como la falta de recursos económicos en momentos de crisis o ante una enfermedad; el correspondiente apoyo recibido por congregaciones no católicas y la indiferencia por parte del gremio católico ante esos momentos críticos; o debido a problemas intrafamiliares que encuentran opciones de solución y apoyo en los no católicos.

Las diversas religiones no católicas que hay en Pantelhó, aunque tienen la idea de que existe un Dios supremo difieren en el modo de interpretarlo y concebirlo. Cada religión tiene una doctrina y manera diferente de cómo acercarse a Dios y cómo alcanzar la salvación divina. De tal modo que aunque se siga el mismo fin, la forma de cómo llegar a éste es distinta, pues cada grupo religioso basa su creencia en la interpretación de la Biblia y en su caso del Libro de Mormón.

Si bien las religiones no católicas mediante sus enseñanzas sustentadas en la Biblia y en el Libro de Mormón, de cómo llevar una vida plena y sana para alcanzar la salvación, han propiciado el cambio en la convivencia familiar y en la conducta del individuo; también han propiciado rupturas en las relaciones familiares entre parientes católicos y no católicos, y el rechazo de prácticas como el compadrazgo (parentesco ritual) o de asumir cargos en las celebraciones patronales. Retomando la idea de Ernest Troeltsch, la disidencia surge de la separación del vínculo que tenía la iglesia católica con el individuo la cual era la encarnación ampliada y permanente de Dios, de tal manera que al desaparecer este vínculo surge toda clase de opiniones humanas las cuales siempre discreparán.

Cada grupo ha formado una identidad religiosa, así para cada individuo es más factible relacionarse socialmente tanto fuera como dentro del templo con los que comparten las mismas creencias religiosas. Es por ello que familiares, amigos y gente de la comunidad terminan sus relaciones intrafamiliares; y en el caso de que aún las sostengan son un tanto limitadas tratando de sobrellevar la situación.?

No podemos negar que el cambio de adscripción religiosa y en su caso la conversión es producto de los factores mencionados. Asimismo reconocemos el éxito de las campañas proselitistas, el altruismo practicado con las personas necesitadas y a su vez el cambio en el estilo de vida que muestran las personas ya conversas y que atrae a otras. No obstante observamos que es necesario también que el candidato a la conversión pase por momentos difíciles en su vida, pues de este modo se encuentra en estado sensible y susceptible para adoptar otra religión.

La impotencia de no poder solucionar problemas de la vida cotidiana hace que el hombre trate de tener un acercamiento divino. Quien cree en Dios siente esta necesidad de comunicarse con él, ya que toda cultura que cree en la divinidad tiene la idea de un ser supremo y poderoso. Al realizar sus prácticas religiosas, las personas expresan sentimientos hacia Dios, con lo cual se fortalecen ya sea para enfrentar los problemas de su existencia o para vencerlos. Estos cambios son 
resultado de la conducta que el converso va adquiriendo en las religiones no católicas, es decir la aceptación de un conjunto de reglas y normas que estas iglesias ejercen sobre los adeptos, las cuales restringen algunas actividades como la veneración de santos y vírgenes, la participación en las festividades de los patronos del pueblo denominados por los evangélicos como fiestas paganas, así como el hábito de fumar e ingerir bebidas alcohólicas, entre otros.

A partir de la diversidad religiosa y los constantes cambios de adscripción la convivencia entre la población del municipio será cismática, los grupos mantendrán sus ideologías religiosas, existirá la idea de que la religión a la que pertenece cada individuo es la verdadera, compitiendo acérrimamente por saber cuál de esas es trascendental para el hombre. Los cambios de adscripción religiosa seguirán sucediendo al igual algunos regresarán al catolicismo. Así también se dará la incursión de nuevos credos religiosos y nuevas formas de proselitismo.

\section{Notas}

${ }^{1}$ Agradecemos la lectura y comentarios hechos al texto que realizaron Felipe Vázquez Palacios y Laureano Reyes Gómez, miembros del cuerpo académico "Organización social e historia”, del IEI.

${ }^{2}$ La edición (2007) sobre la diversidad religiosa en México da cuenta actualizada de la difusión y crecimiento de las religiones y conversos en el país, en ésta Renée De la Torre y Cristina Gutiérrez Zúñiga coordinaron los esfuerzos de varios investigadores quienes destacan que en México el incremento en la diversidad religiosa se presenta de manera heterogénea y Chiapas se cataloga como una de las entidades federativas con mayor impacto de religiones no católicas.

${ }^{3}$ En los conflictos radicales están la expulsión, el secuestro, la agresión física y el homicidio; en los conflictos intermedios están el encarcelamiento, la detención, la destrucción y el despojo de bienes; $y$, en los conflictos de naturaleza intimidatoria clasifican las amenazas de expulsión, las amenazas verbales, la prohibición a los niños de asistir a las escuelas públicas, la prohibición de construcción de templos, el cierre de templos y la destrucción de los mismos (Rivera, Lisbona y García, 2004: 58; Rivera, et al., 2005: 147-148).

${ }^{4}$ Las entrevistas se aplicaron a mestizos, tzotziles y tzeltales, que habitan en la cabecera municipal. Así mismo, se realizó observación participante al interior de los diversos templos y se recurrió a la consulta de datos censales del año 2000 para tener una noción de las proporciones de católicos y no católicos en el municipio, y de censos anteriores donde se presentaron los primeros registros de religiones no católicas.

${ }^{5}$ La información aquí presentada se basa en observación de campo, en la revisión de datos censales y en Köhler, 2007.

${ }^{6}$ Las entrevistas aplicadas a los conversos se enfocaron principalmente en el cambio de adscripción, buscando respuesta a las siguientes preguntas: icómo fue su primer acercamiento a una religión no católica?, ipor medio de quién y de qué forma se acercó a ello?, iqué lo indujo a tomar la decisión de cambiar de religión?, ¿a partir de su conversión qué cambios ha tenido en su vida social y espiritual?, y iqué benéficos e inconvenientes se le han presentado?

Así mismo, se tomaron en cuenta las opiniones de los representantes de iglesias no católicas y de seguidores católicos. El tema a tratar con los pastores o líderes religiosos tuvo su punto de interés en la opinión que tienen sobre la conversión religiosa, se plantearon preguntas como las siguientes: ipor qué la gente cambia de religión?, ¿cómo inició su labor proselitista?, y en su caso ipor qué (el pastor) se cambió de religión?

Las entrevistas a los adeptos católicos, tanto mestizos como tzotziles, se aplicaron a personas que tuvieron algún cargo dentro de la organización religiosa, con el propósito de conocer su sentir hacia los grupos no católicos y su relación con aquellos.

${ }^{7}$ Los informantes no recuerdan el nombre de la estación 
radiofónica.

s"Le presté" se refiere a "pedí prestado".

${ }^{9}$ Aunque en Pantelhó existe otro templo pentecostal donde llega gente mestiza, el entrevistado comentó que no se quiere cambiar a ese templo por el profundo agradecimiento que tiene a los hermanos de esta congregación, que son tzotziles, al contrario, piensa salir a evangelizar para que más gente mestiza asista a esa iglesia.

\section{Bibliografía}

Brown, Peter (2005), "Historia y legitimidad en Los Altos de Chiapas -Pantelhó, dos versiones-", en Anuario de Estudios Indígenas $\chi$, San Cristóbal de Las Casas, Chiapas, México: Instituto de Estudios Indígenas de la Universidad Autónoma de Chiapas, pp. 199-216.

De la Torre, Renée y Cristina Gutiérrez Zúñiga [coordinadoras] (2007), Atlas de la diversidad religiosa en México, México: Centro de Investigaciones y Estudios Superiores en Antropología Social (CIESAS), El Colegio de Jalisco, El Colegio de la Frontera Norte, El Colegio de Michoacán, Universidad de Quintana Roo, Subsecretaría de Población, Migración y Asuntos Religiosos de la Secretaría de Gobernación, Consejo Nacional de Ciencia y Tecnología (CONACYT).

Fabre Platas, Danú A. (2001), "Conversión Religiosa e Imaginario Social: El discurso como elemento de análisis", en Convergencia, mayo-agosto, año 8, núm. 25, Toluca, México: Universidad Autónoma del Estado de México, Facultad de Ciencias Políticas y Administración Pública, pp. 277-308.

Garma Navarro, Carlos (1988), "Los estudios antropológicos sobre el protestantismo en México”, en Antropología nuevas perspectivas, México: Universidad Autónoma Metropolitana, pp. 53-65.

Garma Navarro, Carlos (2005), “Cambio religioso en localidades indígenas del sureste mexicano según el censo del 2000”, en Ruz, Mario H. y Carlos Garma Navarro (coordinadores), Protestantismo en el mundo maya contem- poráneo, México: UNAM-UAM, pp. 25-48.

Köhler, Ulrich (2007), Santa Catarina Pantelhó, Tuxtla Gutiérrez, Chiapas, México: UNICACH.

Lisbona Guillén, Miguel (2004), "La emergencia del conflicto religioso en el municipio de Las Margaritas, Chiapas: El caso del ejido Justo Sierra”, en LiminaR. Estudios sociales y humanísticos, Año 2, vol. II, núm.2, diciembre, México: Centro de Estudios Superiores de México y Centroamérica de la Universidad de Ciencias y Artes de Chiapas, pp. 48-60.

López Cortés, Eliseo (1990), Pentecostalismo y milenarismo. La Iglesia Apostólica de la Fe en Cristo Jesús. México: Universidad Autónoma Metropolitana, Texto y Contexto.

Molinari, Claudia (1998), "Protestantismo y cambio religioso en la Tarahumara: apuntes para una teoría de la conversión", en Elio Masferrer K. (compilador), Sectas o iglesias viejos o nuevos movimientos religiosos, México: ALER, Plaza y Valdés Editores, pp. 191-205.

Pitarch, Pedro (2004), "La conversión de los cuerpos. Singularidades de las identificaciones religiosas indígenas", en Liminar. Estudios sociales y humanísticos, Año 2, vol. II, núm.2, diciembre, México: Centro de Estudios Superiores de México y Centroamérica de la Universidad de Ciencias y Artes de Chiapas, pp. 6-17.

Rivera Farfán, Carolina, et al. (2004), Chiapas religioso, Lecturas para entender Chiapas, Tuxtla Gutiérrez, Chiapas, México: Secretaría de Educación del Gobierno del Estado de Chiapas.

Rivera Farfán, Carolina, et al. (2005), Diversidad religiosa y conflicto en Chiapas. Intereses, utopías y realidades, México: Centro de Investigaciones y Estudios Superiores en Antropología Social, Universidad Nacional Autónoma de México, Gobierno del estado de Chiapas.

Rivera Farfán, Carolina (2005), "El proselitismo evangélico en la depresión central de Chiapas", en Ruz, Mario H. y Carlos Garma Navarro (coordinadores), Protestantismo en el mundo maya contemporáneo, México: UNAM-UAM, pp. 129-154.

Robledo Hernández, Gabriela Patricia (1987), Disidencia 
y religión: Los expulsados de San Juan Chamula, México: ENAH, Tesis de licenciatura.

Secretaría de Industria y Comercio (1963), VII Censo General de Población 1960, México: Dirección General de Estadística del Estado de Chiapas.

Troeltsch, Ernest (1925), El protestantismo y el mundo moderno, Fondo de Cultura Económica, México.

Vázquez Palacios, Felipe R., (1999), La gran comisión: "Id y predicad el evangelio", un estudio de interacción social y difusión religiosa, México: CIESAS.

Villasana Benítez, Susana (2002), Sociodemografía de la familia. Estudio de la adscripción religiosa de las familias zoques de Tapalapa, Chiapas, 1985-1997, Tuxtla Gutiérrez, Chiapas, México: Instituto de Estudios Indígenas-Universidad Autónoma de Chiapas, Serie Monografías 7.

Zebadúa Luna, José Antonio (2008), Cambio de adscripción reli- giosa. Causas y efectos de la conversión religiosa en Pantelhó, Chiapas, México, San Cristóbal de Las Casas, Chiapas, México: Tesis de licenciatura en sociología. Facultad de Ciencias Sociales de la Universidad Autónoma de Chiapas.

\section{Consulta en línea}

INEGI, XII Censo general de población y vivienda 2000, http://www.inegi.gob.mx.

INEGI, II Conteo de población y vivienda, 2005, http:// www.inegi.gob.mx

Molinari, Claudia 1995, "El protestantismo en la Tarahumara", en Dimensión, Revista en línea antropológica, vol. 4, México, http://www.dimensionantropologica.inah.gob.mx. 